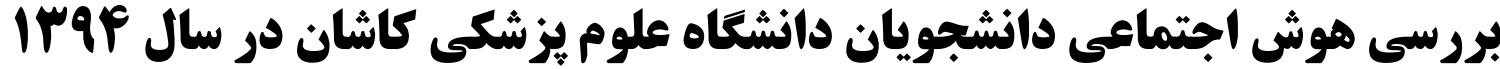

\author{
حميد رحيمى ا:**، هماسادات افتخار r
}

'دكترى مديريت آموزشى، استاديار و هيات علمى دانشكده علوم انسانى، دانشكاه كاشان، كاشان، ايران

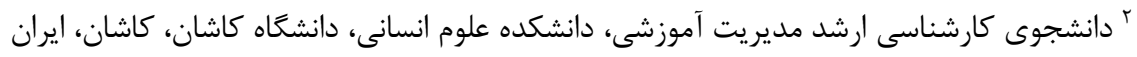

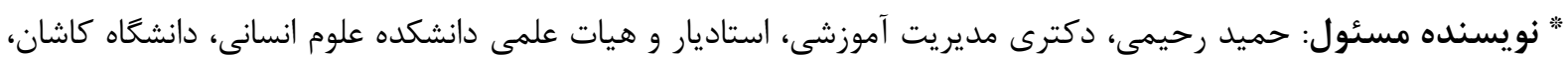
كاشان، ايران. ايميل: dr.hamid.rahimi@kashanu.ac.ir

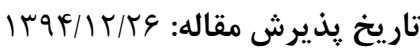

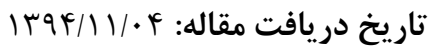

\section{جكيده}

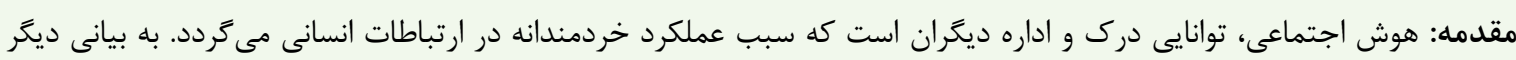

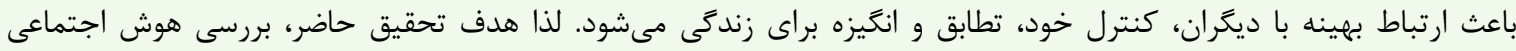

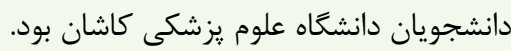

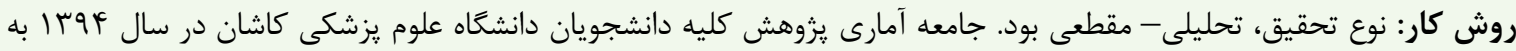

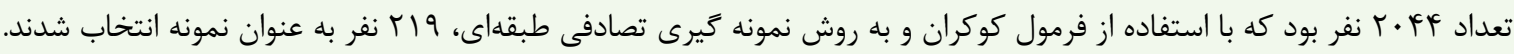

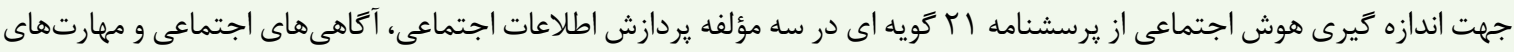

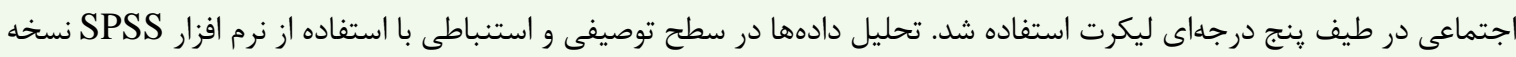

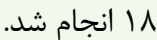

يافتهها: يافتهها نشان داد ميانكَين هر يك از مؤلفههاى هوش اجتماعى از ميانكَين فرضى ؟ بيشتر بود. بالاترين ميانكَين مربوط به

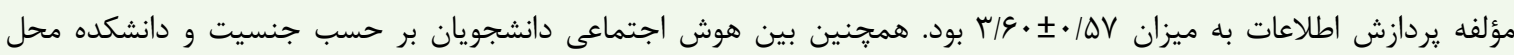

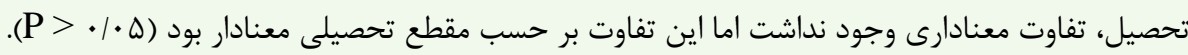

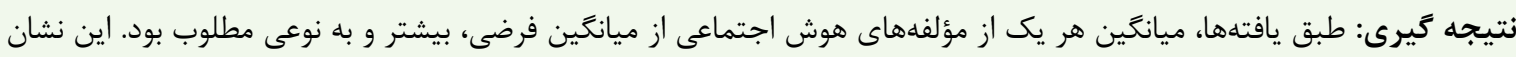

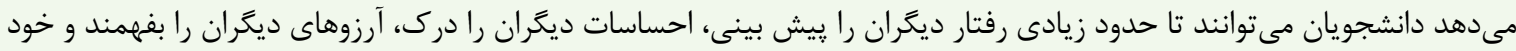

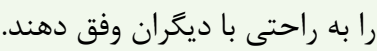
كليدوازهها: هوش اجتماعى، دانشجويان علوم يزشكى، دانشكاه

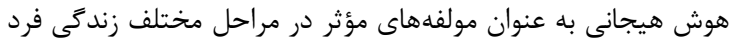

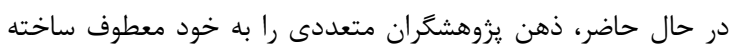

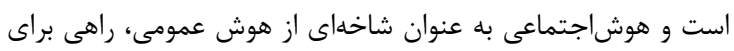

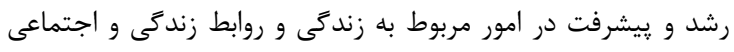

$$
\text { محسوب مى مَردد (ז). }
$$
هوش اجتماعى مجموعهاى از ظرفيتهاى غيرشناخ (باختى، توانش ها و و

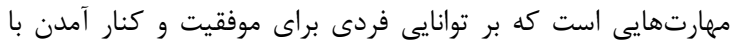

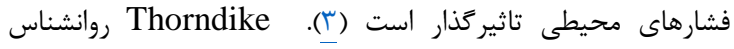

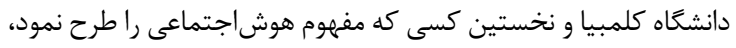

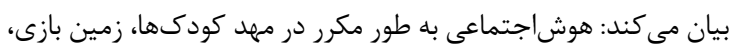

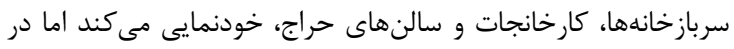

هوش يكى از وجوه قابل توجه در سازش يافتكى افراد با محيط و نيز به

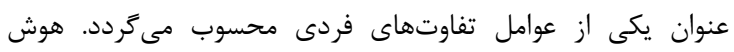

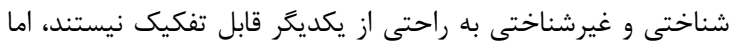

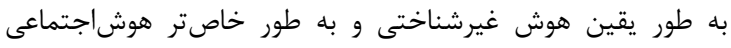

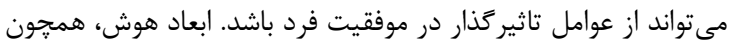

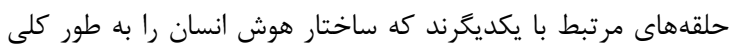

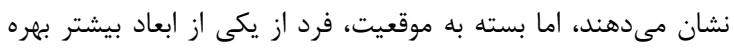

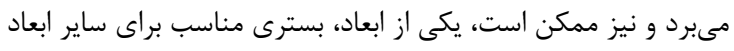

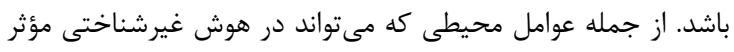

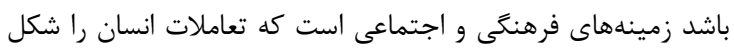

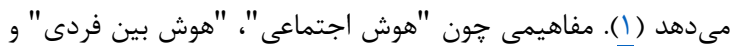


اجتماعى دانشجويان دانشكده كلرادو امريكا دريافت كه ميانكَين

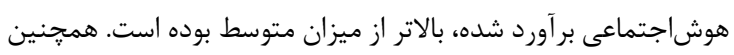

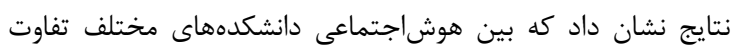

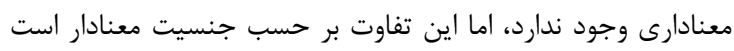

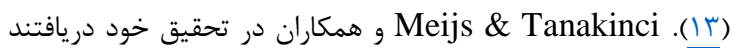

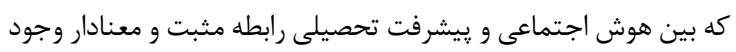

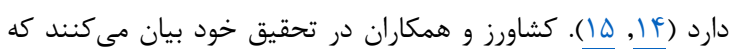

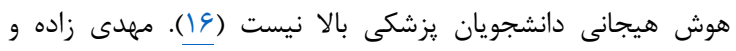

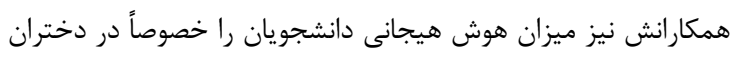

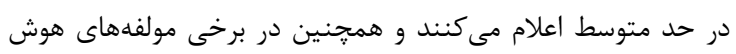

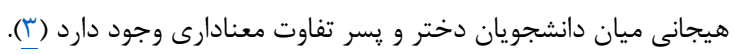

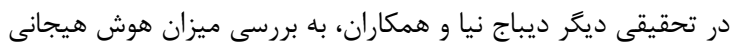

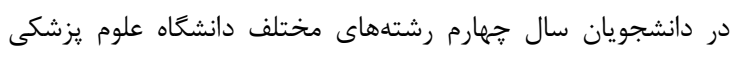

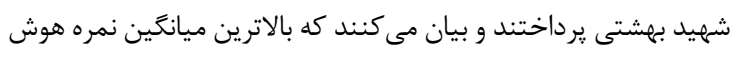

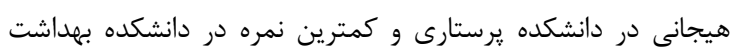

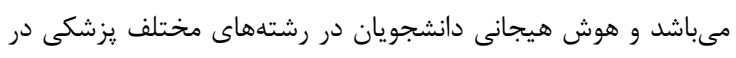

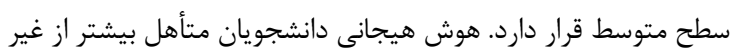

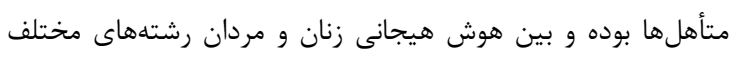

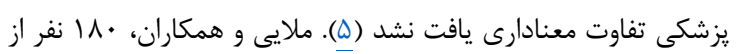

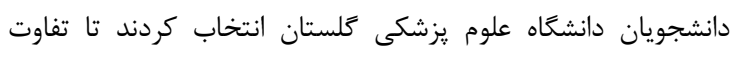

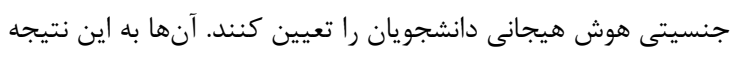

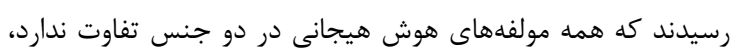

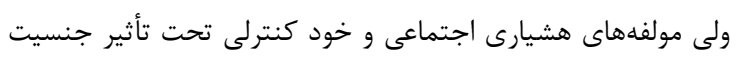

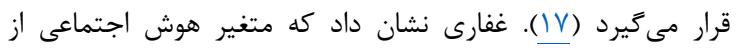
قوىترين متغيرها براى بيش بيش بينى عملكرد تحصيلى دان دانشجويان

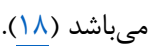

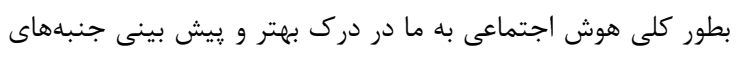

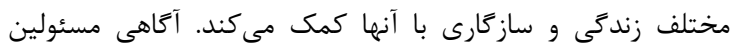

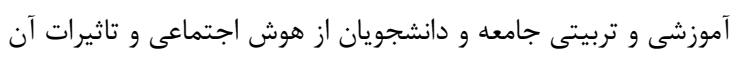

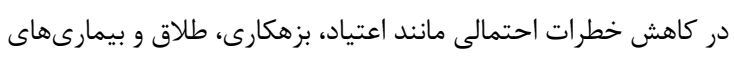

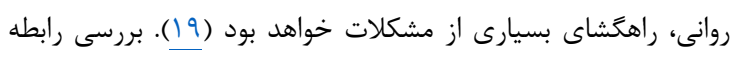

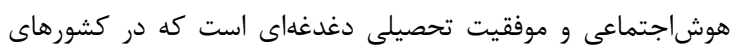

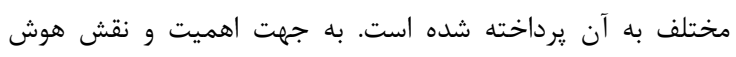

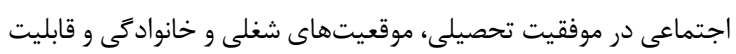

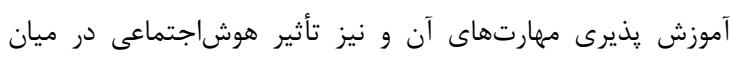

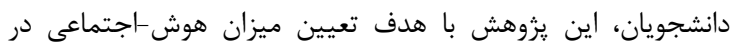

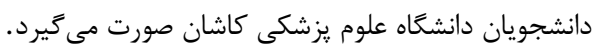

\section{روش كار}

با توجه به اينكه اين تحقيق به بررسى هوش اجتمار بارى دارى دانشجويان

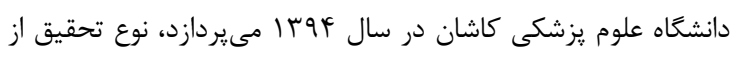

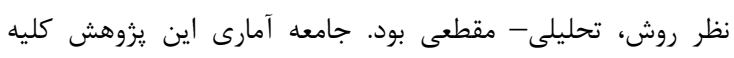

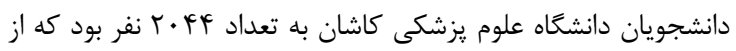

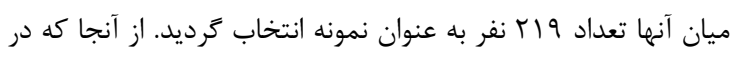

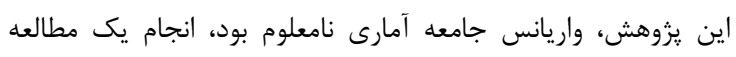

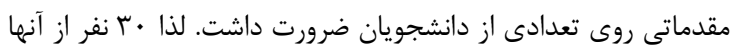

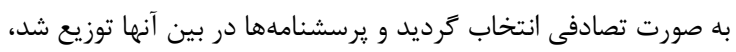

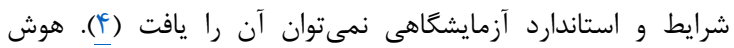

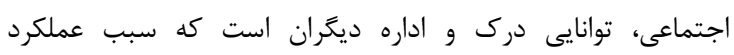

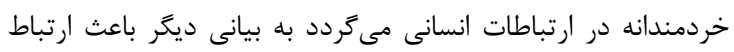

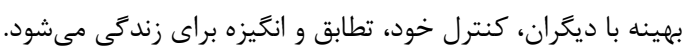
Golman

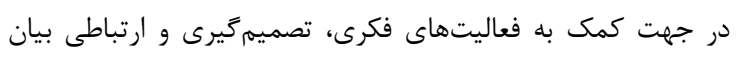

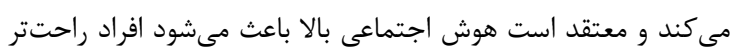

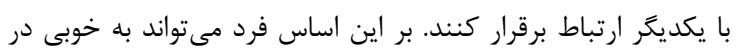

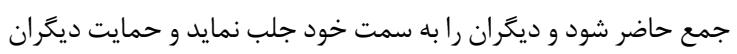

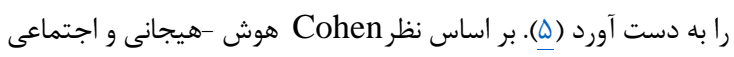

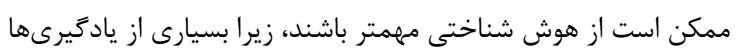

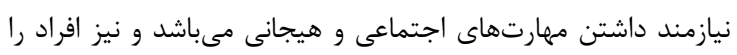

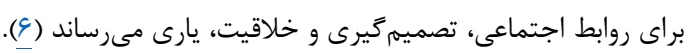
Silvera

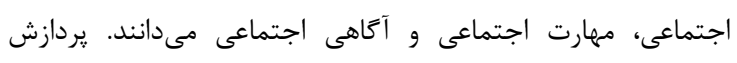
الطلاعات اجتماعى بر توانايى درك و فهمه و بيش بيش بينى رفتار و واحساسات

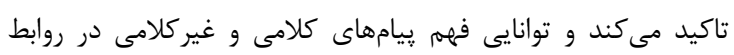

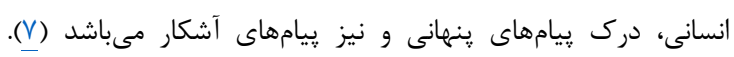

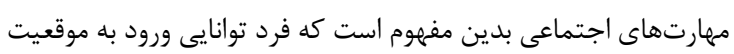

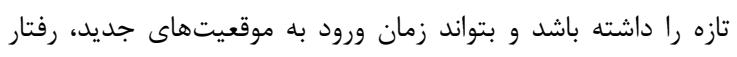

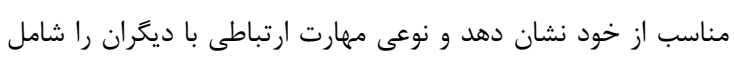

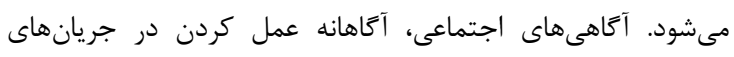

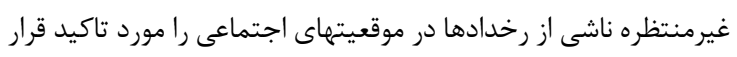

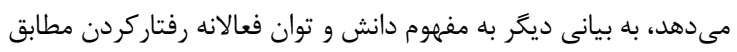

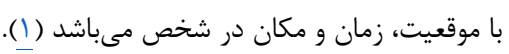
Bar On

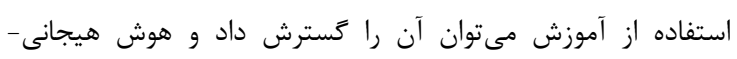

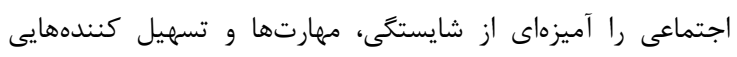

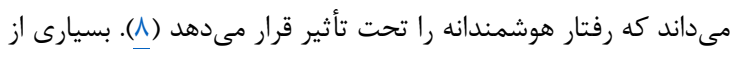

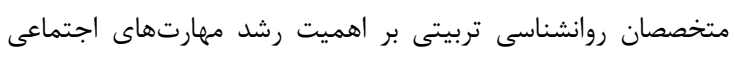

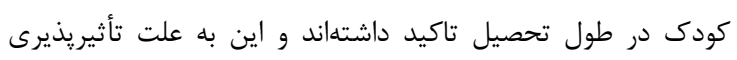

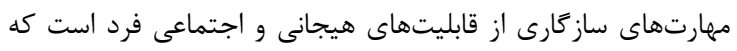

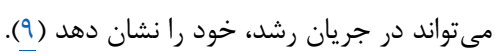

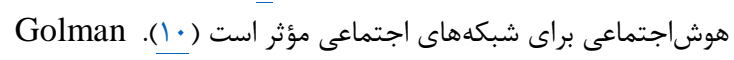

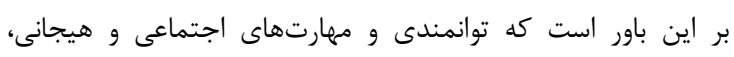

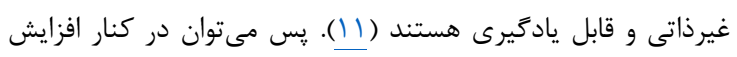

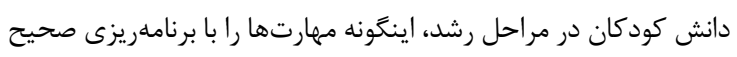

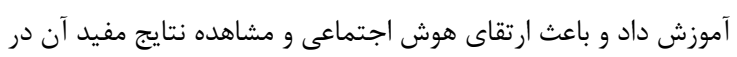

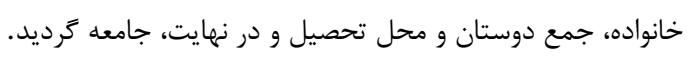

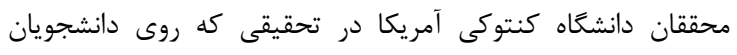

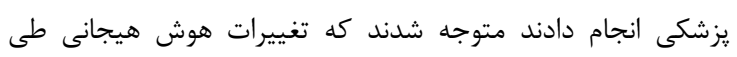

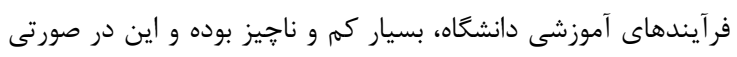

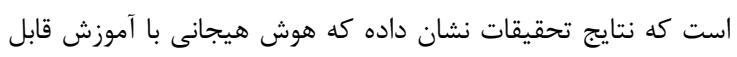

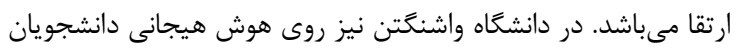

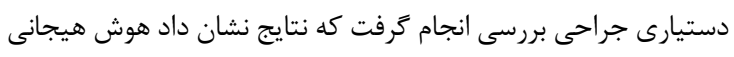

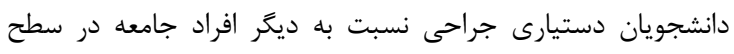

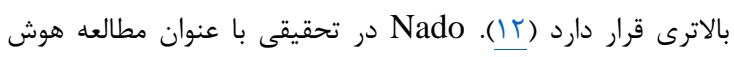




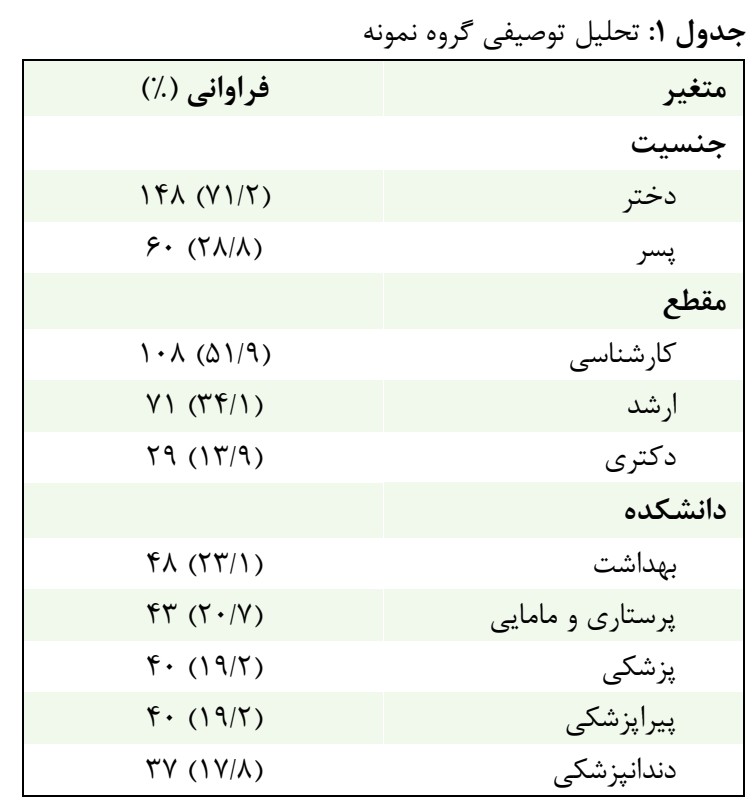

بر اساس يافتهها، بيشتر افراد گروه نمونه، بر حسب جنسيت، دانشجويان

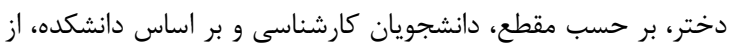

دانشكده بهداشت بودند.

فرضيه ا: ميانگين هوش اجتماعى دانشجويان دانشگاه بالاتر از حد بد متوسط است.

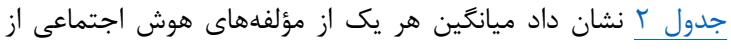

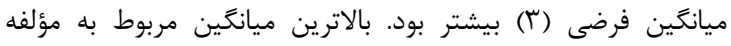

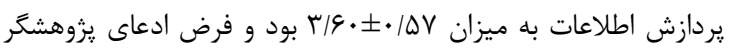

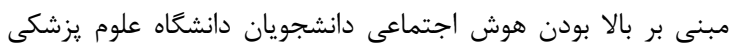

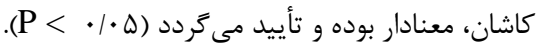

جدول r: مقايسه ميانكين هوش اجتماعى دانشجويان با ميانكين

\begin{tabular}{|c|c|c|}
\hline $\mathbf{P}$ & ميانغين & متغير \\
\hline$\cdot 1 \cdot \cdot 1$ & $\Gamma / 9 \cdot \pm \cdot / \Delta V$ & يردازش اطلاعات \\
\hline$\cdot 1 \cdot \cdot 1$ & $r / f \mid \pm \cdot / \varphi q$ & آكاهى هاى اجتماعى \\
\hline$\cdot 1 \cdot \cdot 1$ & $r / 4 q \pm \cdot / q r$ & مهارت اجتماعى \\
\hline$\cdot 1 \cdot \cdot 1$ & $r / \Delta \pm \cdot / 4 \varphi$ & هوش اجتماعى \\
\hline
\end{tabular}

فرضيه ז: بين هوش اجتماعى دانشجويان دانشعاه بر حسب ويثزَى هاى

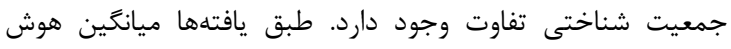

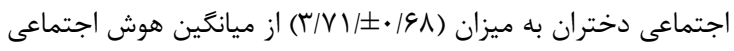

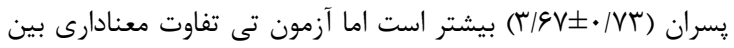

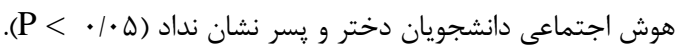

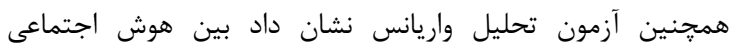

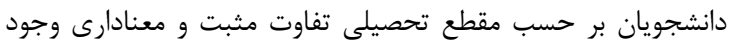

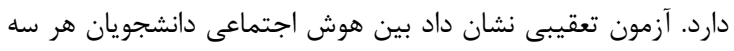

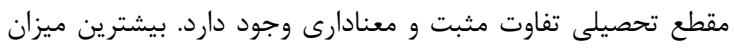

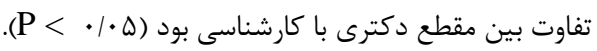

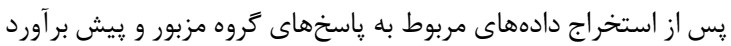

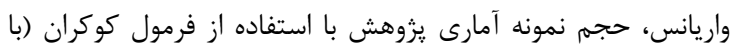

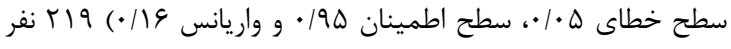

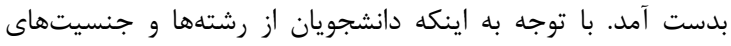

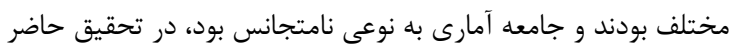

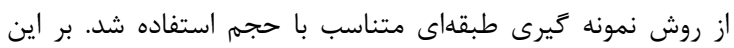

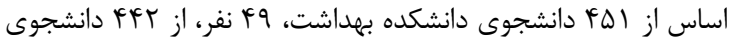

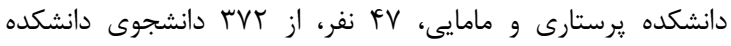

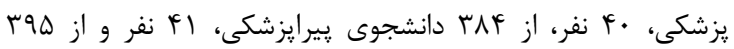

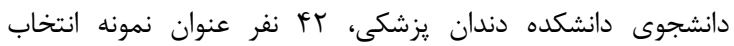

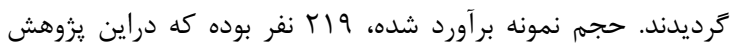

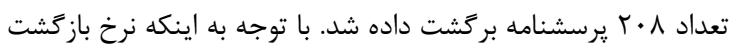

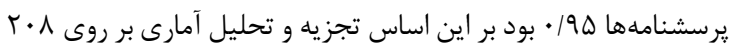

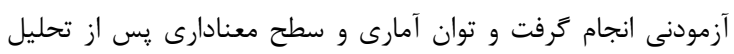

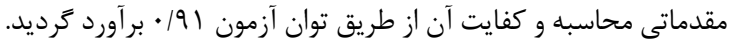

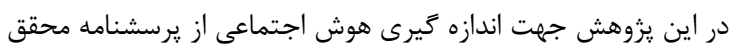

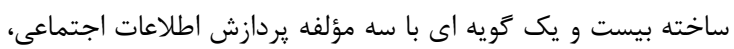

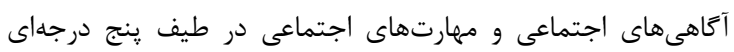

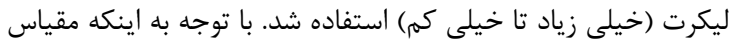

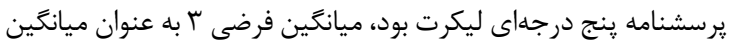

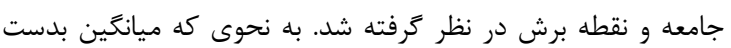

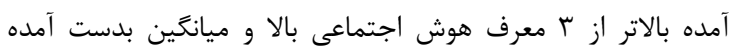

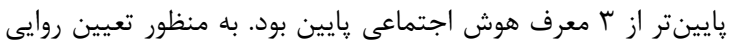

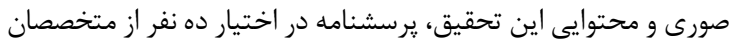

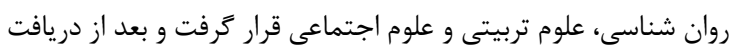

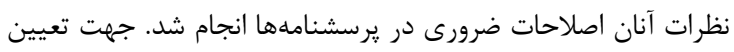

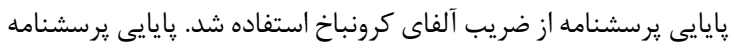

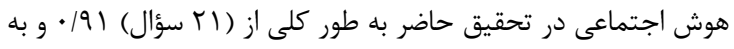

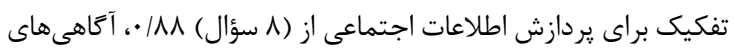

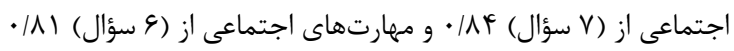

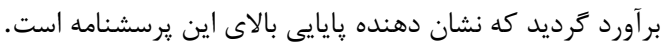

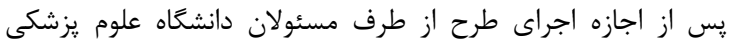

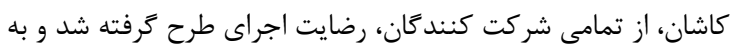

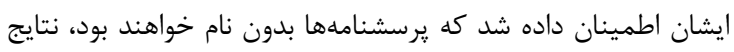

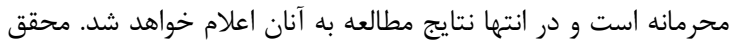

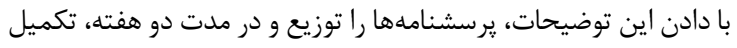

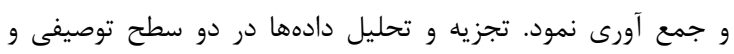
استنباطى با استفاده از نرم افزار SPSS نسخه

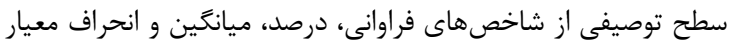

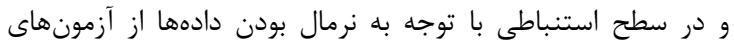

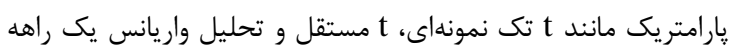
استفاده كرديد.

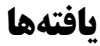
در جدول 1 تحليل توصيفى گروه نمونه به صورت فراوانى و درصد بر حسب جنسيت، مقطع تحصيلى و دانشكده محل تحصيل ارائه شده 
يا كاهش هوش اجتماعى تأثير زيادى ندارد. نتايج تحقيق حاضر با نتايج

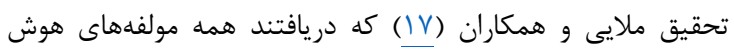

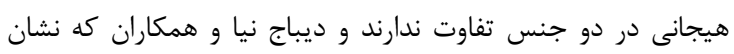

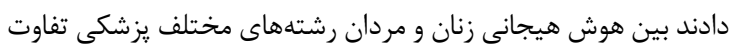

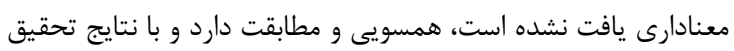

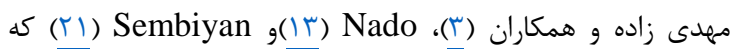

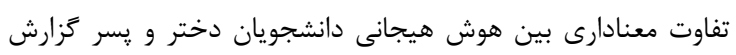

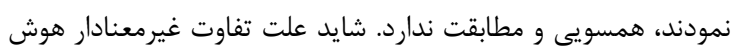

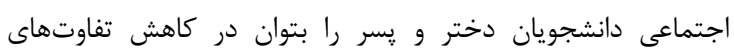

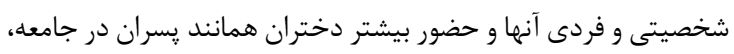

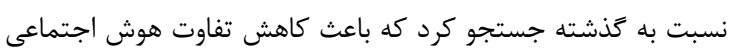
دانشجويان دختر و يسر شده است.

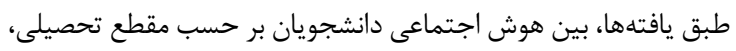

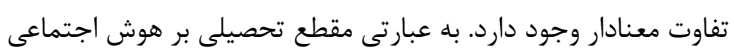

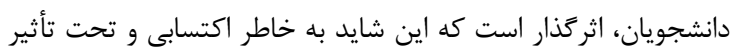

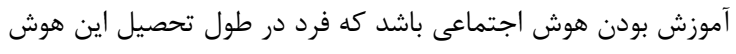

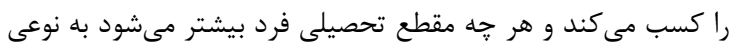

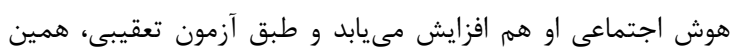

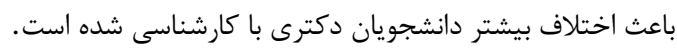

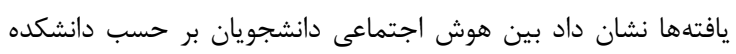

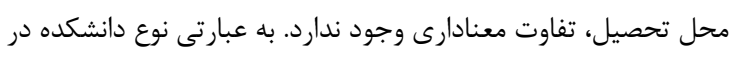

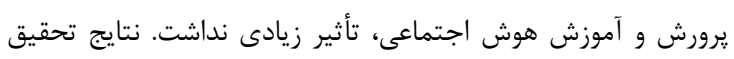

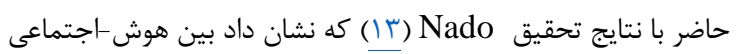
دانشكدهاى مختلف تفاوت معنادارى وجود ندارد و

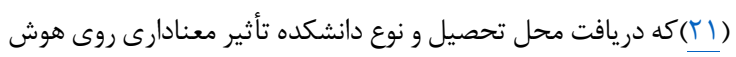
اجتماعى ندارد، همسويى و مطابقت دارد.

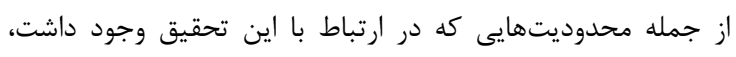

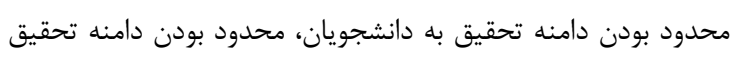

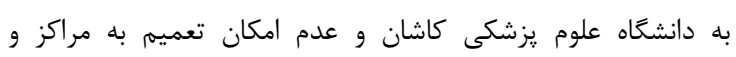

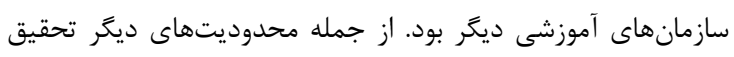

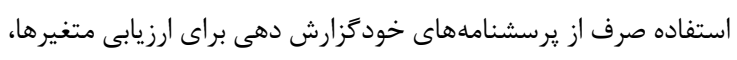

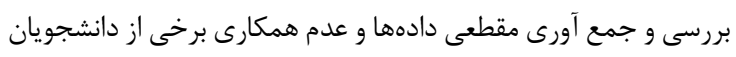

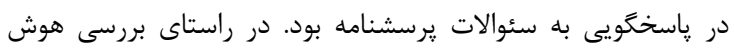

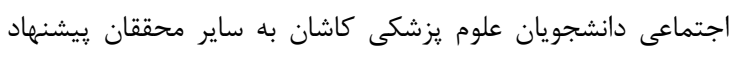

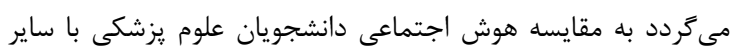

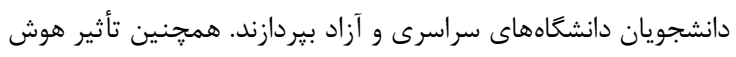

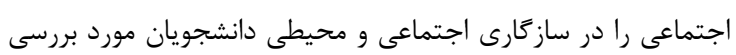
قرار دهند.

\section{نتيجه كيرى}

طبق يافتهها، ميانگين هر يك از مؤلفههاى هوش اجتماعى از ميانگين

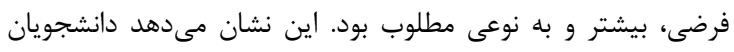

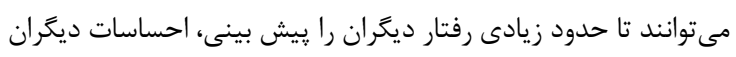

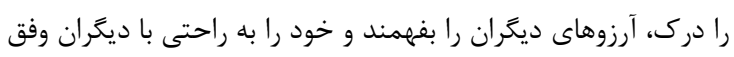

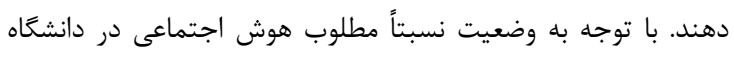

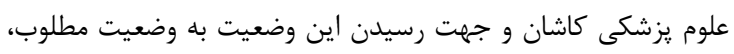

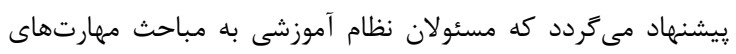

همجنين هوش اجتماعى دانشجويان دانشكده يرستارى و مامايى به

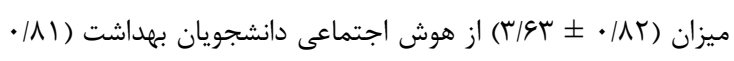
دن

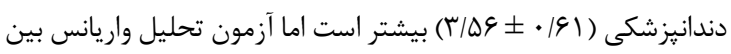

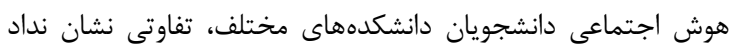

$(\mathrm{P}<\cdot / \cdot \Delta)$

دانشجويان در زمينه توانايى سازكار بودن افكار و رفتار خود با تغييرات

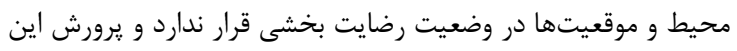

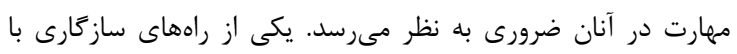

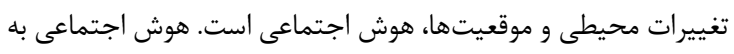

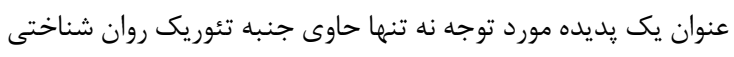

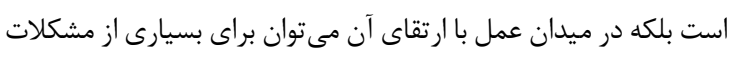

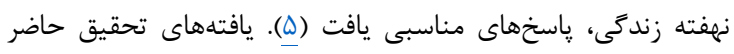

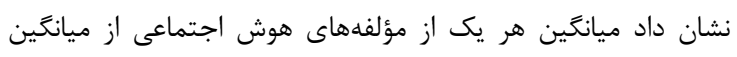

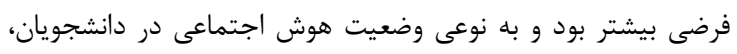

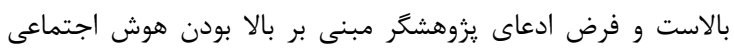

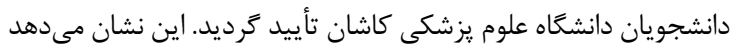

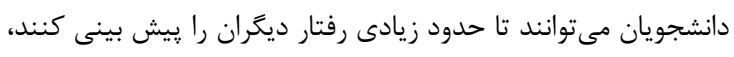

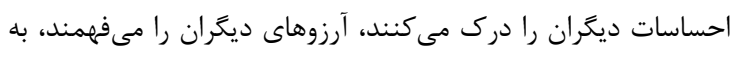

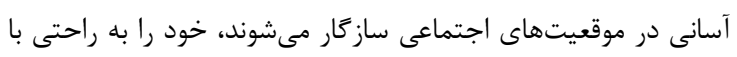

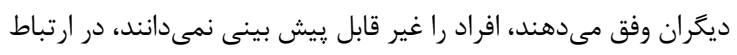

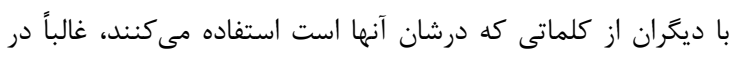

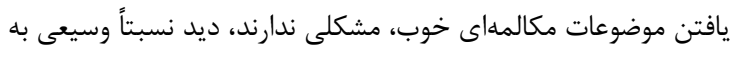

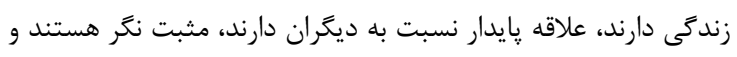

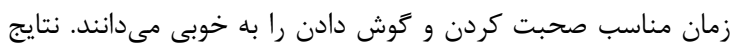

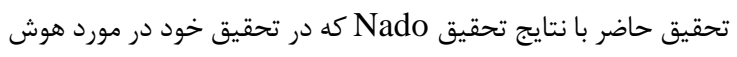

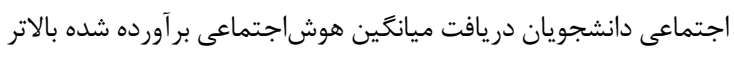

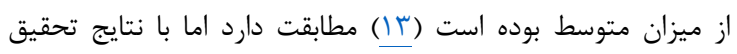

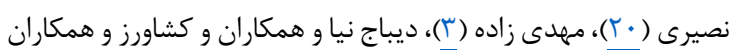

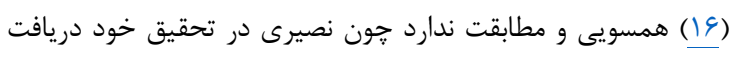

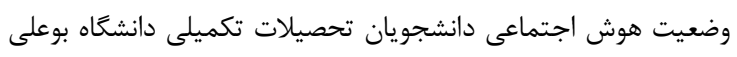

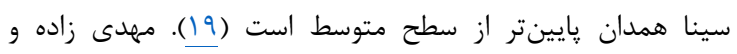

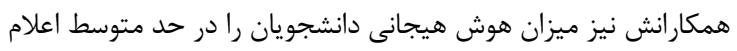

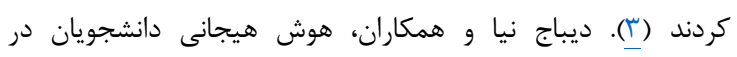

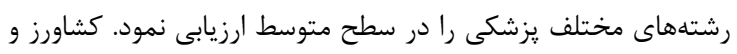
همكاران در تحقيق خود هوش هيجانى دانشجويان علوم يزشكى شئ شيراز

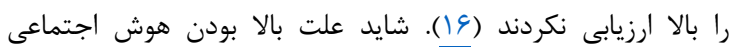

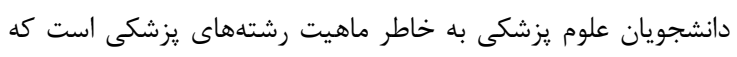

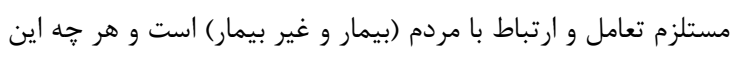

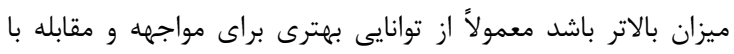

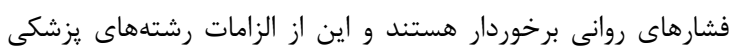

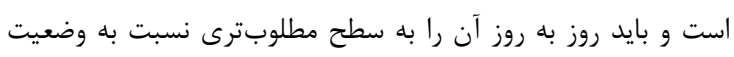
فعلى برسانند.

يافتهها نشان داد بين هوش اجتماعى دانشجويان دختر و يسر، تفاوت

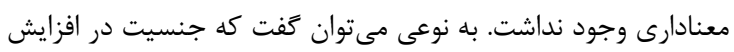


درك مناسب از نخرانى ها و احساسات سايرين در فعاليتهاى اجتماعى بركزار كنند.

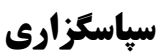

نويسندًان بر خود لازم مى دانند از كليه مديران و دانشجويان دانشكاه

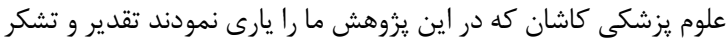

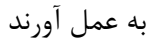

\section{References}

1. Saadatmand M. [The relationship between social intelligence and ability to absorb their knowledge at the government girl's secondary school]. Mashhad: Mashhad Ferdowsi University; 2008.

2. Nouraei M, Saei I. [The effect of social intelligence on educational performance of faculty members (case study: Islamic Azad University)]. J Behav Sci. 2010;3(2):155-83.

3. Mehdizadeh H, Azizi M, Jamshidzadeh F. [A study of emotional intelligence among students of Medical Universities in country west]. J Health Sys Res. 2011;7(1):89-100.

4. Buzan T. The power of social intelligence. New York: Perfect Pound Publisher; 2002.

5. Goleman D. Working with emotional intelligenc. New York: Bantam Books; 1998.

6. Bahrami M, Kareshki $\mathrm{H}$, editors. [Review and compare master emotional intelligence and selfregulation in master degree students of humanities sciences and engineering]. 1st National Conference on the Findings of Cognitive Science in Education, 2011; 2011; Mashhad, Iran: Civilica.

7. Silvera DH, Martinussen M, Dahl TI. The Tromso Social Intelligence Scale, a self-report measure of social intelligence. Scand J Psychol. 2001;42(4):3139. PMID: 11547906

8. Bar On R, Parker JDA. Handbook of emotional intelligence. San Francisco: Jossey- boss; 2006

9. Yarmohammadian A, Sharafirad H. [The relationship between emotional intelligence and social compatibility in adolescents]. J Appl Soci. 2011;44(4):35-50.

10. Freshman B, Rubino L. Emotional intelligence skills for maintaining social networks in healthcare organizations. Hosp Top. 2004;82(3):2-9. DOI: 10.3200/HTPS.82.3.2-9 PMID: 15754856

11. Golman K, Axelsson O, Johannesson H, Mansson S, Olofsson C, Petersson JS. Parahydrogen-induced polarization in imaging: subsecond (13)C angiography. Magn Reson Med. 2001;46(1):1-5. PMID: 11443703

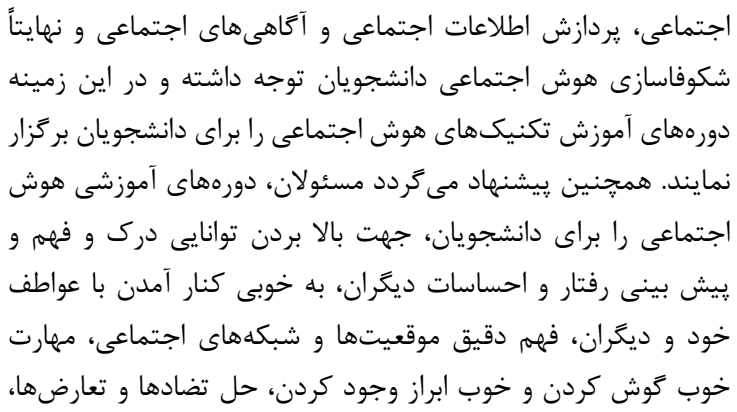

12. Soltanifar A. Emotional intelligence. J Mental Health. 2007;9(35):83.

13. Nado T. A study on social intelligence of college students. Int J Cur Res. 2012;4(1):231-2. DOI: 10.20546/ijcrar.2016.402.002

14. Tanakinci $\mathrm{O}$, editor The impact of social intelligence on academic achievement of students studying media. 10th International Conference Multidisciplinary Scientific Geo, 2010; 2010; Sydney, Australia: SGEM Scientific Papers Database.

15. Meijs N, Cillessen AH, Scholte RH, Segers E, Spijkerman R. Social intelligence and academic achievement as predictors of adolescent popularity. $\mathrm{J}$ Youth Adolesc. 2010;39(1):62-72. DOI: 10.1007/s10964-008-9373-9 PMID: 20091217

16. Keshavarz N, Amini M, Mani A, Nabeiei P, Saffari Z, Jafari M. A study of relationship between emotional intelligence and academic achievement in students of Shiraz University of Medical Sciences. J Media. 2014;5(3):70-7.

17. Molaei E, Asayesh H, Taghvakish B, Ghorbani M. Gender difference and emotional intelligence in Golestan University of Medical Sciences' Students. J Nurs Midwife. 2011;2(8):30-4

18. Ghaffari M, Hajlo N, Bayami S. [The Relationship between social and moral intelligence with academic performance of Medical Students in Maragheh and Bonab]. JNE. 2015;4(3):48-55.

19. Zahiroddin A, Dibajnia P, Gheidar Z. [Evaluation of emotional intelligence among students of 4 th grade in different medical majors in Shahid Beheshti University of Medical Sciences]. Pejouhandeh. 2010;15(5):204-7.

20. Nasiri F. [Relationship between social intelligence and citizenship behavior with educational effectiveness in students at University of Hamedan]. N App Educ Manage. 2014;5(1):175-88.

21. Sembiyan R. A study of social intelligence of college students. Int J Cur Res. 2012;4(1):231-2. DOI: $\underline{10.20546 / i j c r a r .2016 .402 .002}$ 


\title{
A Study of Social Intelligence in Students at Kashan University of Medical Sciences During Year 2015
}

\section{Hamid Rahimi ${ }^{1, *}$, Homa Sadat Eftekhar ${ }^{2}$}

\author{
${ }^{1} \mathrm{PhD}$ of Learning Management, Assistant Professor and Faculty of Humanities, University of \\ Kashan, Kashan, Iran \\ ${ }^{2}$ MSc Student of Learning Management, Department of Education, Faculty of Humanities, University \\ of Kashan, Kashan, Iran \\ * Corresponding author: Shahrbano Talebi, Hamid Rahimi, PhD of Learning Management, Assistant \\ Professor and Faculty of Humanities, University of Kashan, Kashan, Iran. E-mail: \\ dr.hamid.rahimi@kashanu.ac.ir
}

Received: 24 Jan 2016

Accepted: 16 Mar 2016

\begin{abstract}
Introduction: Social intelligence, the ability to understand and deal with others, allows wise human communication. In other words, it leads to optimal communication with others, self controls, compliance and motivation for life. Thus, the purpose of this research was to study social intelligence in students at Kashan University of Medical Sciences during year 2015.

Methods: The type of research was sectional-analytical. The research population included all students at Kashan University of Medical Sciences $(n=2044), 219$ of which were selected as the sample using the Cochran Formula and stratified random sampling. The data was collected using social intelligence questionnaire with 21 items in three components (social information process, and social awareness and social skills), scored with a five-point Likert scale. Data analysis was done at descriptive level and inferential level by SPSS 18 statistical software.

Results: Findings showed that mean social intelligence components was higher than average. The highest mean score was related to social information process $(3.60 \pm 0.57)$. Also, there were no significant differences between social intelligence in terms of gender and college, yet this difference was significant on basis of the academic course.

Conclusions: On basis of the findings, student's social intelligence level was higher than average and was desirable. This showed that students can largely predict the behavior of others, understand others' feelings and wishes, and adapt easily to others.

Keywords: Social Intelligence; Students of Medical Science; University
\end{abstract}

(C) 2016 Iranian Nursing Association (INA) 